UNIVERSITÀ POLITECNICA DELLEMARCHE DIPARTIMENTO DI ECONOMIA

\title{
The IdENTIFICATION OF SUb-CENTRES IN TWO ITALIAN METROPOLITAN AREAS: A FUNCTIONAL APPROACH
}

\author{
PAOLO VENERI \\ QUADERNO DI RICERCA n. 343
}

Luglio 2010 
Comitato scientifico:

Renato Balducci

Marco Crivellini

Marco Gallegati

Alberto Niccoli

Alberto Zazzaro

Collana curata da:

Massimo Tamberi 


\title{
The Identification of Sub-centres in Two Italian Metropolitan Areas: a Functional Approach
}

\author{
Paolo Veneri \\ Research Fellow at the Dipartimento di Economia \\ Università Politecnica delle Marche \\ P.zza Martelli, 8 \\ 60121 Ancona - Italy \\ p.veneri@univpm.it
}

\begin{abstract}
This work introduces a method aimed at the identification of metropolitan sub-centres. Instead of using traditional and static methodologies based on morphological approaches (e.g. employment density), interaction measures have been employed, based on the Central Place theoretical tradition. In particular, tools of social network analysis and a measure of productive completeness have been utilised, so as to take into account the capacity of sub-centres to organise their surrounding territory. The degree of nodecentrality has been calculated using data about commuting for working reasons and the methodology has been applied to the metropolitan areas of Rome and Milan. Results have been compared with those obtained from the application of Giuliano and Small's (1991) thresholds in jobs density and absolute employment and confirm the soundness of the proposed approach for Italian metropolitan areas.
\end{abstract}

JEL codes: R10, R12, R14

Key words: sub-centres, polycentricity, metropolitan areas

\section{Introduction $^{1}$}

Contemporary metropolitan areas (MAs) are characterised by ever more complex spatial structures that are increasingly different from the archetype of the monocentric city. In the last two decades, metropolitan employment has been scattered throughout the urban territory, changing the traditional patterns of urban spatial organisation towards dispersed or polycentric structures. In fact, despite the assumption that MAs constitute a unified labour market, these are normally characterised by overlapping localised labour markets (Shearmur and Motte, 2009). In addition, agglomeration externalities - whose role on economic growth and productivity is increasingly studied - have extended geographically beyond the boundaries of single urban cores and are increasingly shared among different interconnected centres (Meijers and Burger, 2010). For these reasons, the analysis of polycentricity at the metropolitan level has gained the

\footnotetext{
${ }^{1}$ This work is part of a wider research project on cities and metropolitan areas, which is being carrying out at the Department of Economics of the Marche Polytechnic University. The author is grateful to Antonio G. Calafati, Rafael Boix and Richard Shearmur for their helpful comments at different stages of this work.
} 
attention of many scholars who aim at understanding the causes and the effects of this model of spatial organisation. Furthermore, polycentricity is also thought of as a normative tool to reach important objectives in terms of environmental sustainability and social cohesion (Davoudi, 2003). As a matter of fact, measuring polycentricity and, more generally, urban spatial structure - has become an important research topic.

On analysing polycentricity, a necessary step concerns the identification of metropolitan sub-centres, which could be seen as the first step in the characterisation of polycentric metropolitan areas. This could be seen as an independent topic with autonomous relevance, because it allows the recognition of the places where the priorities of public investments are assigned, as well as a wider knowledge of metropolitan spatial organisation, which is necessary for any spatial planning policy. In addition, if it is accepted that external economies of agglomeration have regionalised their space of influence, as it has been argued in the literature (Richardson, 1995), then polycentric urban structures could have a role in enhancing this source of economic advantages. Only by providing reliable tools to measure urban spatial structure it would be possible to verify the effects of polycentricity on economic performances, a topic which is still empirically understudied.

The aim of this work is the identification of metropolitan sub-centres in two Italian metropolitan areas - Rome and Milan - through a methodology based on an interaction and functional approach. The majority of works aimed at the identification of employment sub-centres adopt morphological and density-based methodologies, which are based on the bid-rent theoretical tradition (Alonso, 1964; Muth, 1969; Mills, 1972). The latter approaches are particularly sound when new sub-centres emerge as a consequence of processes of employment decentralisation from the Central Business District (CBD) to the hinterland, due to high congestion and land prices. This is the case of most metropolitan areas, especially in the United States. The procedure of sub-centre identification proposed in this work, however, is more closely connected with the Central Place theoretical tradition (Christaller, 1933; Lösch, 1940), which is particularly suitable for European - and especially for Italian - MAs. In fact, European MAs emerge mostly as the result of an integration or coalescence process between old and preexisting cities (Champion, 2001; Calafati, 2002), rather than a decentralisation process from a single and congested Central Business District (CBD).

The identification of metropolitan sub-centres is carried out in this work by analysing the functional characteristics of places, rather than their morphological features. Thus, in order to identify metropolitan sub-centres, (commuting) flows between urban nodes (municipalities) have been analysed, together with the supply of urban functions. Considering these aspects allows us to draw a hierarchic ranking between places and to identify those municipalities that turn out to be more central. On the other hand, restricting the analysis on population and density patterns within MAs does not allow the recognition of the actual degree of node-centrality, since, in order to build a hierarchical ranking, interaction measures are always necessary (Lukermann, 1966).

This paper is organised as follows. In section 2 a review of the literature is carried out, distinguishing the major static and morphological methodologies from those that use flows and that are based on a interaction approach. Section 3 explains the procedure that is employed in this work to identify metropolitan sub-centres, while section 4 presents the results of such a procedure for Rome and Milan MAs. Results are also 
compared with those using the most common and straightforward density-based methodology of Giuliano and Small (1991). Finally, section 5 concludes.

\section{Literature review}

\subsection{Static methodologies}

The literature on the identification of sub-centres has grown rapidly in the last twenty years, improving its degree of rigorousness and adaptability to different territorial contexts. The most commonly employed methodologies to identify sub-centres make use of density measures. This is because of the meaning that is given to the concept of centre (or sub-centre). In fact, a metropolitan centre could be thought of as a place characterised by a high concentration of employment and activities with respect to the surrounding territory. Hence, this definition works particularly well for metropolitan areas that grow and evolve mainly by decentralisation from a congested CBD towards new concentrations of activities (sub-centres), due to a trade-off between economies and diseconomies of agglomeration.

In a chronological order, one of the first straightforward methods of identification is probably that of Giuliano and Small (1991), which is based on employment and density thresholds. The two authors identify 32 sub-centres in the Los Angeles MA by selecting those transportation analysis zones (TAZs) that show an employment density of at least 10 jobs per acre and a total employment of at least 10000 units. The same method - but with different cut-off values - has been adopted by many other authors, such as Song (1994), Small and Song (1994), Bogart and Ferry (1999), Anderson and Bogart (2001) and Cervero and Wu (1998). They analyse, respectively, the metropolitan areas of Los Angeles, Cleveland and San Francisco ${ }^{2}$. These simple cut-offs, however, are subject to a certain degree of discretion, since this method is often guided by trials and errors, as well as by some local knowledge of the place under analysis (McMillen, 2001 - p. 449). However, a certain degree of discretion is used in every method of identification, even in econometric ones, where certain statistical confidence levels have to be chosen.

Another methodology based on simple cut-offs is that employed by Shearmur and Coffey (2002), which - following the idea of McDonald (1987) - identifies as subcentres the contiguous TAZs that show an employment to resident workers ratio $(\mathrm{E} / \mathrm{R}$ ratio) greater than 1 and a number of jobs of at least 5000 units. This method should be actually classified somewhere in between static and dynamic approaches, since it approximates the net in-commuting, even if it does it by using stock data. The E/R ratio is preferred over employment density by some authors because the former approximates the capacity of attraction of employment more accurately (Shearmur and Coffey, $2002-$ p. 579) ${ }^{3}$. However, it puts less emphasis on employment localisation. Giuliano and Small (1991 - p. 167), in fact, argue that E/R ratio does not sufficiently take into account agglomeration economies, which depend on the distance between firms (density) rather than on the presence of resident workers.

\footnotetext{
${ }^{2}$ More precisely, Anderson and Bogart (2001) analyse a sample of four metropolitan areas: Cleveland, Indianapolis, Portland and St. Luis.

${ }^{3}$ For a more detailed analysis of the advantages and disadvantages of the E/R ratio for the identification of subcentres, see Coffey and Shearmur (2002), Forstall and Greene (1997), Baumont and Bourbon (2002).
} 
A third methodology is based on the identification of local density peaks. Following this approach, the zones which present a local maximum in employment density or in the E/R ratio, with respect to the surrounding area, can be considered sub-centres. Following the idea of Bender $(1981 ; 1985)$ on the effects of sub-centres on land prices, McDonald (1987) identifies sub-centres by looking at local peaks in the E/R ratio. Similar approaches can be found in McDonald and McMillen (1990), while Gordon et al. (1986), Craig and $\mathrm{Ng}$ (2001) and Redfearn (2007), among others, look at local peaks in employment density. In the last two studies authors identify local peaks using a nonparametric specification of the density function, in order to avoid what in their opinion are excessively strong assumptions regarding the spatial distribution of sub-centres. In fact, in most cases the analysis starts from the assumption of a monocentric structure (Muth, 1969; Mills, 1972), estimating a simple negative exponential density function (Kemper and Schmenner, 1974). Another possibility is the assumption of a polycentric urban structure, adopting a parametric density function with multiple centres (Gordon et al., 1986).

A fourth method consists in the identification of the residues of an econometric estimation of the density function, which can be parametric or non-parametric, depending on the strength of the assumptions on the urban structure. The residues that are statistically diverse from zero can be considered candidate sub-centres (McDonald and Prater, 1994; McMillen, 2001). These selected nodes are then analysed in terms of their effects on urban spatial structure, through the estimation of a polycentric model of employment density. A recent work by Leslie (2010) identifies Phoenix sub-centres with a Kernel smoothing process for both employment and establishment density. Using Kernel density measures with point data has the advantage of allowing a minor bias in the spatial definition of centres due to administrative boundaries and land uses. McMillen and Lester (2003) argue that econometric methods are more objective and work better for comparative analysis among different metropolitan areas. However, for the analysis of metropolitan areas over time, simple threshold methods are usually preferred.

A fifth morphological method uses spatial statistics tools to identify - within a metropolitan area - clusters of zones with higher density than that of surrounding ones. High-density clusters can be considered sub-centres, since they represent relative concentrations of employment. This approach is based on the Local Indexes of Spatial Autocorrelation (LISA) (Anselin, 1995). With these indicators it is possible to quantify the degree of clustering of neighbouring zones with high levels of density (Riguelle et al., 2007). This method has been used, among others, by Baumont et al. (2004) and by Guillain et al. (2004).

\subsection{Interaction methodologies}

The functional approach based on interaction procedures seems particularly sound for Europe, which is characterised by a lot of small, historically determined urban centres. European metropolitan areas formed mostly by territorial coalescence (Calafati, 2002, 2009) rather than by decentralisation from a congested CBD. More in depth, during the first wave of growth of city boundaries - when urbanisation was accelerating speedily - the expanding metropolitan areas absorbed the small-sized nearby centres, 
through a process of absorption (Champion, 2001; Muñiz et al., 2005). During the last fifty years, on the other hand, cities have continued to expand spatially, but at a slower rate than the expansion of their field of influence. Hence, metropolitan areas have grown by integration (Champion, 2001), which consists mostly in a relational concept rather than a physical one.

The majority of European metropolitan areas are the result of such a process of coalescence and are characterised by a dominant centre, which is surrounded by other smaller centres, forming contemporary polycentric metropolitan areas. Most European metropolitan sub-centres did not result from a simple process of decentralisation of the city centre. They were pre-existent to the formation of MAs and they still play the role of central places for at least a fraction of the metropolitan territory, even without a particularly high employment density. Theoretically, the most important framework for the interpretation of sub-centring in European metropolitan areas is the Central Place theory (Christaller, 1933; Lösch, 1940), since it focuses on urban functions and on hierarchies between territorial nodes. From this perspective, metropolitan sub-centres can be seen as the central places within a given metropolitan area, the places that organise, functionally, their surrounding territory. Since the Nineties, however, this theoretical framework has been partially re-thought in terms of horizontal relations between centres, rather than hierarchical ones, giving rise to the network of cities paradigm (Camagni and Salone, 1993; Batten, 1995; Dematteis, 1990). This perspective is based on the idea that different centres specialise in different sectors in order to benefit from Marshallian economies of location and relate to one another in a nonhierarchic way. This theoretical framework is particularly sound for the study of urban systems and inter-metropolitan links, while for single metropolitan areas - as is the case in this work - the traditional central place theory can still play an important role.

Instead of considering only static and morphological features, such as employment density, the literature on the identification of metropolitan sub-centres includes some interaction methods, which make use of flow data. This kind of studies can be found both in America (Bourne, 1989; Gordon et al., 1989) and in Europe (Clark and Kluijpers-Linde, 1994; Burns et al., 2001). Bourne (1989) visually analyses commuting flows for Canadian cities. Gordon et al. (1989), on the other hand, follow a tripgeneration density approach for Los Angeles, analysing the distribution of traffic flows among TAZs. In Europe, Burns et al. (2001) identify sub-centres in Spanish metropolitan areas by selecting the municipalities that show a net entry flow of at least $15 \%$.

More recently, these interaction approaches have been used also for the analysis of spatial configuration at the level of national urban systems (Limtanakool et al., 2007; 2009) or even at the global level (Derudder et al., 2003). More specifically, the former studies propose a set of spatial interaction indices, trying to quantify the strength and the symmetry of interaction and the structure of the whole network (urban system), by using data about commuting flows. In some few other works, commuting flows have been used to investigate the interdependence of suburbs and central cities within MAs (Holly, 1993; Barbonne et al. 2007; Gilli, 2002). In particular, Holly (1993 - p.419) argues that commuting approximates the actual interaction between cities (exchange of labour, thus of knowledge and information), making clear the different position of each city in the metropolitan hierarchy. 
Interaction methods are deeply different from those based on employment density and on other morphological features. In fact, underlying these two alternative perspectives there are two different concepts of metropolitan sub-centre and, consequently, two different concepts of polycentricity. Gordon and Richardson (1996) argue that with dynamic methodologies it is possible to grasp the role of sub-centres not only as employment concentrations, but also as focal points of a metropolitan area, regarding the urban functions that sub-centres supply to their neighbour territory. This standpoint makes it possible to shift from a morphological approach to a functional one, where sub-centres are conceived as places that have the capacity to organise their surrounding area.

\section{Methods and data}

This section proposes a methodology for the identification of metropolitan sub-centres, which combines interaction and functional elements. Before starting to describe the methodology that has been adopted, it is worth to spend some words on the units of analysis. Polycentricity is a multi-scalar concept, which can be referred at three different spatial levels: country, inter-urban/regional and urban level (Davoudi, 2003). In this work the latter level of analysis has been chosen, hence sub-centres have been identified and selected among all the urban nodes located within each metropolitan area. Since Italy still lacks an official definition of MAs, the latter have been taken from a recent work by Boix and Veneri (2009) - which provide the identification of all Italian MAs by adopting an algorithm inspired at the 1990 methodology of the U.S. Federal Register (Office of Management and Budget, 1990).

The procedure starts from the conceptualisation of MAs as networks of cities (municipalities). Networks are made up of two main components, which are urban nodes (municipalities) and the links between each node (commuting flows). Defining metropolitan areas as networks of cities - or as systems of cities - enables us to use concepts and tools of systems theory to analyse them (Boix, 2002). Moreover, most of the indicators of network analysis can be usefully employed to mathematically quantify the relations between urban nodes within a given MA. The idea consists in studying the centrality structure of MAs, concentrating at the way in which each urban node relates to the others. Hence, central places can be identified analysing the way in which relationships are distributed within MAs, rather than at the static characteristics of the territory.

Using data of flow instead of data of stock can allow this. More in depth, many indicators of centrality can be borrowed from network analysis in order to quantify the how each node play a central role in the network. The most simple, robust and easy-tointerpret indicator is the degree of centrality (Freeman, 1979), which, in asymmetrical networks, - such as MAs are - can be approximated by the in-degree (Costembader and Valente, 2003 - p. 291; Zemljič and Hlebec, 2005 - p. 82). The in-degree index represents the number of links that directly enter in each node. At the same time, the out-degree is the number of links that directly exit from each node. Hence, in order to detect those municipalities that exert a central role in the metropolitan network, a flowcentrality ratio $\left(F C_{i}\right)$ has been computed on the base of the following formula: 


$$
F C_{i}=\frac{\sum_{j=1}^{N} l_{j i}}{\sum_{i=1}^{N} z_{j i}}
$$

where the numerator and the denominator are, respectively, the in-degree and the outdegree indicators for the $i$-th municipality of a given MA; $l_{i j}$ is the number of links towards the municipality $i$ from the $j$-th municipality of the MA under analysis. At the same time, $z_{j i}$ is the number of links that from the $i$-th municipality towards the other $j$ th municipalities of the same MA. The centrality of each nodes is directly proportional to the numerator and inversely proportional to the denominator. This occurs because a municipality which captures most of the flows reveals its capacity to dominate its surrounding territory from a functional point of view.

The $F C_{i}$ ratio has been calculated for every municipalities of the two most important Italian MAs: Rome and Milan, as identified in Boix and Veneri (2009). Such a ratio has been calculated by using 2001 data of commuting flows between municipalities, provide by the Italian National Institute of Statistics (Istat). For each MA there is a matrix of commuting flows, which contain the number of commuters from every municipality to all the others of the same MA.

The procedure of sub-centre identification proposed in this work is developed following three steps. Firstly, the $F C_{i}$ ratio has been calculated for all municipalities within each MA. Then, all the municipalities with a value of the $F C_{i}$ ratio higher than 1 have been considered candidate sub-centres. Initially, these selected nodes are considered only "second order" sub-centres because work-commuting flows do not represent all the movements that take place in MAs, shaping the hierarchies of their subareas. Urban nodes can indeed be relevant - or central - also for activities related to consumption, study and leisure. As a consequence, it is necessary to distinguish the general concept of employment sub-centre from that of urban sub-centre. While the former can be correctly identified using the in-degree indicator alone, the latter requires some other measure to grasp the actual capacity of sub-centres to organise their surrounding territory through the supply of a wider set of urban functions.

Therefore, as a second step, another indicator - named productive completeness $\left(P C_{i}\right)$ - has been calculated for all municipalities of the two MAs. This indicator approximates the variety of functions supplied by each urban node, starting from the idea that, besides attracting a great number of commuters, a metropolitan sub-centre must have a minimum degree of productive variety, which can be thought of as a sign of the wide range of urban functions supplied by a given node. The $P C_{i}$ index can be calculated as follows:

$$
P C_{i}=s_{i} / \hat{s}
$$

where $P C_{i}$ is the productive completeness for the $i$-th municipality; $s_{i}$ is the number of 5 digit sectors with at least one job in 2001, using Istat Census data; $\hat{s}$ is a parameter indicating the average number of 5 digit sectors in each MA. The aim of this indicator is to grasp the urban character of candidate sub-centres, through an attempt to measure 
urbanisation economies (Jacobs, 1969) and similarly to what has been done in Compagnucci (2009). In other words, central nodes must show typical urban characteristics, such as completeness and diversity of their sectorial structure. Since the aim of this second step is that of catching the capacity of each municipality to supply the widest variety of functions, the number of sectors has been preferred to other measures of productive diversity, like the Hirschman-Herfindahl index. The latter is more appropriate for catching the extent to which the employment of a given economic system is specialised in few sectors or evenly distributed in wider set of activities.

The third step of the procedure consists in selecting, for each MA, those municipalities for which both $F C_{i}$ ratio and $P C_{i}$ index are higher than 1 . Those municipalities satisfying both criteria $\left(F C_{i}\right.$ and $P C_{i}$ higher than 1$)$ can be considered as first order sub-centres or, in other words, metropolitan sub-centres. This method also makes it possible to grasp a scale factor without imposing a total population or employment threshold. In fact, a larger dimension is associated with a higher value of both centrality $\left(F C_{i}\right)$ and completeness $\left(P C_{i}\right)^{4}$. The results of the proposed methodology are reported in the next section, applied to Rome and Milan MAs.

\section{Results}

In this section the results of the above-mentioned procedure are reported and compared with those emerging using the traditional density-based method of Giuliano and Small (1991). As regards the methodology proposed in this work, figure 1 visually represents the commuting flows among municipalities in the two selected MAs ${ }^{5}$. In the lower part of the figure, all the flows toward the pivot municipalities have been cleaned off for the clarity of visual interpretation. The figure highlights the typical polycentric structure of Milan, with a number of central nodes surrounding the pivot municipality. Each central node is clearly visible, corresponding to the thickening of links. The $F C_{i}$ ratio is adopted in order to catch how thick each node is, which means how central each node is. While Milan has quite a large number of sub-centres all around the pivot municipality, Rome's spatial structure appears to be less polycentric, with few central nodes and with the prominent role of the pivot municipality.

Figure 2 shows in darker colour the municipalities that have been identified as metropolitan sub-centres These municipalities are characterised by both a high internal attractiveness $\left(F C_{i}\right.$ ratio - they are already 'second-order' sub-centres) and a high productive completeness $\left(P C_{i}\right.$ index higher than 1). Milan confirms its typical polycentric spatial structure, while the same thing cannot be said for Rome, which appears to have a much smaller number of sub-centres. The adopted methodology identifies 4 sub-centres for Rome and 11 in the case of Milan. All the metropolitan subcentres of the two MAs are listed in table 1.

\footnotetext{
${ }^{4}$ The Pearson coefficient of correlation between total employment and the in-degree index for all the considered municipalities is 0.89 , while the correlation between total employment and the PC index is 0.36 .

${ }^{5}$ In order to make the figure more easy to read, each matrix has been dichotomised, with the value of 1 for the 4 nodes with the higher in-degree.
} 
Figure 1 Visual representation of links within the DMA of Rome and Milan (flows of commuters for working reasons)

a) Rome
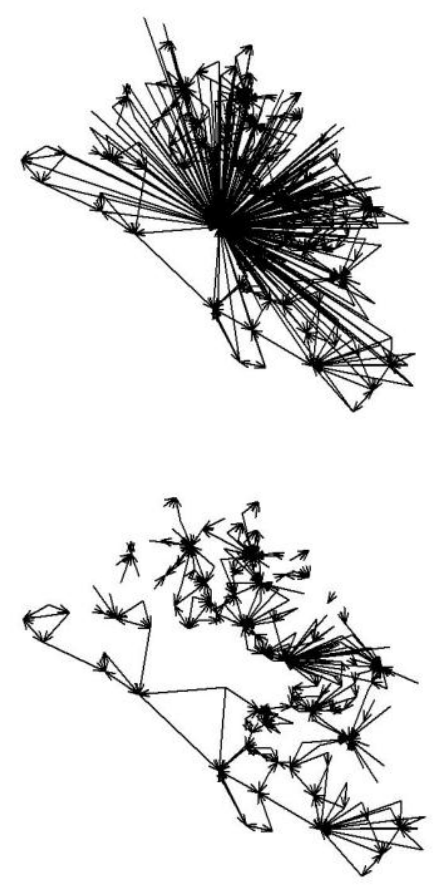

b) Milan
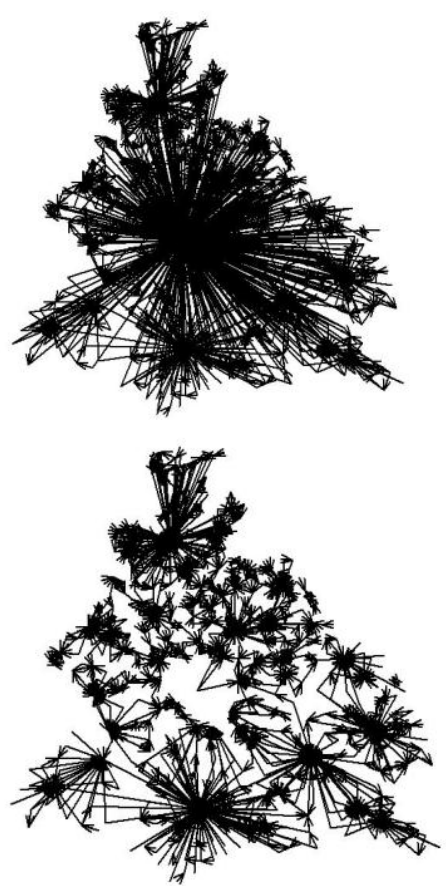

Figure 2 Metropolitan sub-centres of Rome and Milan
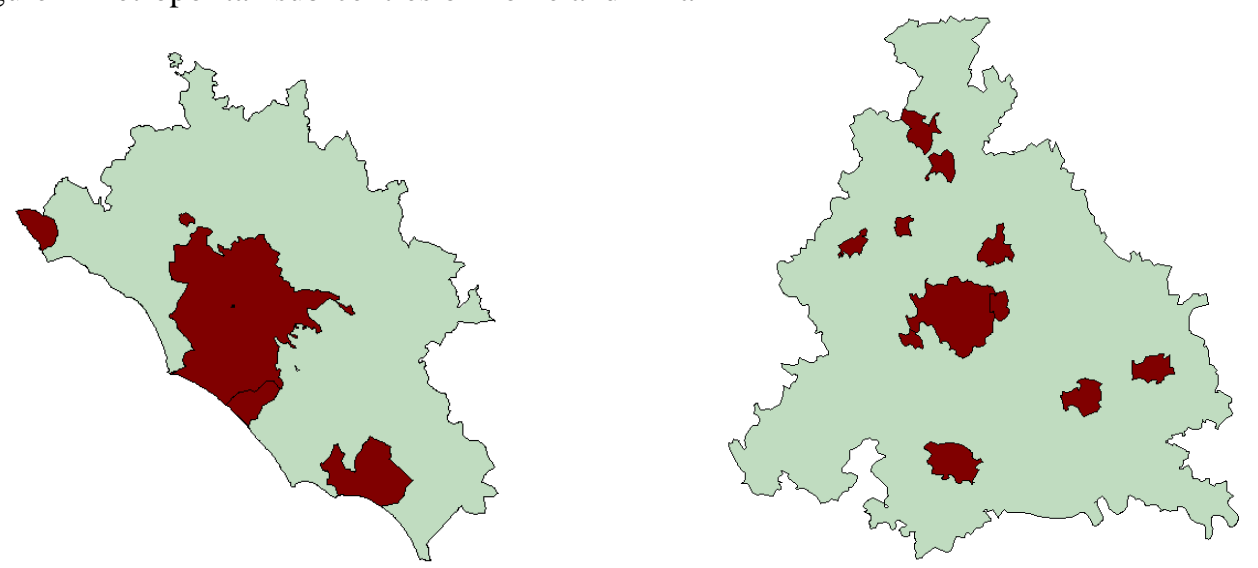

Table 1 List of metropolitan sub-centres in Milan and Rome MAs 
The results obtained with the proposed approach can be compared with those emerging from the application of the traditional and threshold-based procedure introduced by Giuliano and Small (1991). The authors identify two thresholds beyond which a place can be considered a sub-centre. The first is the total number of jobs, which must be at least 10000 units and the second is an employment density of at least 10 jobs per acre. Using these thresholds, sub-centres of Rome and Milan have been identified again and shown in figure 3.

Figure 3 Sub-centres of Milan and Rome, identified with the Giuliano and Small's (1991) method
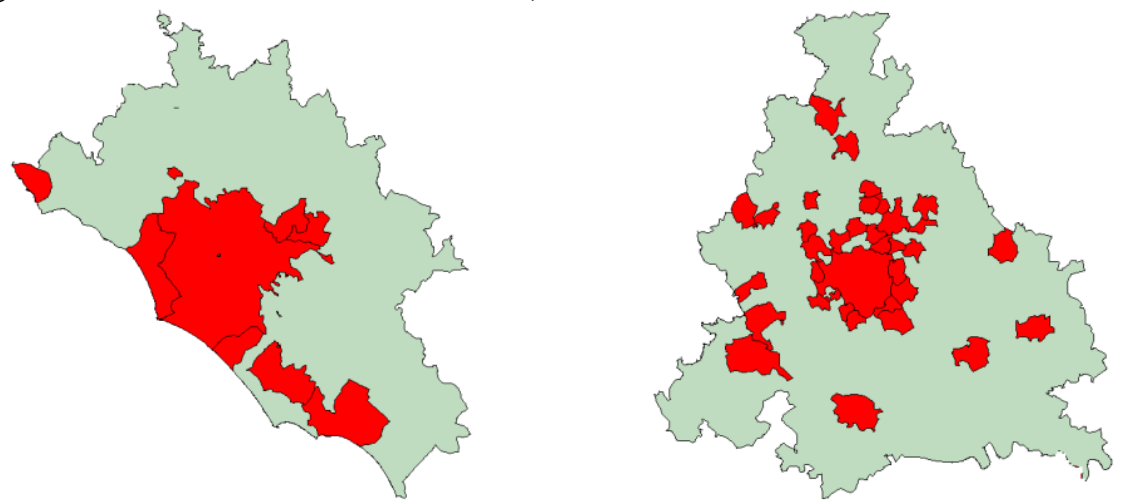

Comparing the results of the two methodologies (figures 2 and 3), it emerges that with Giuliano and Small's procedure a higher number of sub-centres is identified. Probably, by simply adjusting density and employment thresholds, it would be possible to obtain very similar results. However, a more relevant difference between the two approach can be observed more clearly by observing the maps (figures 2 and 3). Looking at Milan, for example, it appears that with the density-based approach of Giuliano and Small almost all the pivot's first belt municipalities - plus many of the second belt - are considered sub-centres. This is a comprehensible result, since density tends to decrease from the pivot's peak towards the hinterland. However, considering those first and second belt municipalities sub-centres does not seem to be sound, since they are not proper central places, but just high-density nodes, due to their proximity to the pivot. These nodes, indeed, do not show a high capacity of attraction and, most importantly, do not present a complete productive structure. They could be considered sub-centres only by conceptually aggregating them to their respective pivot municipalities in a single territorial unit, which could be thought of as a city de facto (Calafati and Veneri, 2010). Hence, if the aim is to identify sub-centres, interaction approaches seem to work with more thinness.

\section{Concluding remarks}

In this work a functional methodology has been proposed for the identification of metropolitan sub-centres. Differently from other approaches that are mainly based on 
morphological measures (e.g. employment density), this method focuses on the relational dynamics among urban nodes that take place within metropolitan areas. To do this, MAs have been conceptualised as systems of cities (municipalities) and the centrality of each city has been valued with an indicator $\left(F C_{\mathrm{i}}\right)$ that measures the capacity of each municipality of catalysing flows from the surrounding territory. Then, after checking the functional power of each node - through an index of productive completeness, $P C_{i}-$ sub-centres of Rome and Milan have been identified.

By comparing the functional procedure proposed in this work with that of Giuliano and Small (1991), the former appears to work well both from a theoretical and from an empirical point of view. Theoretically, a functional approach is more appropriate to study the central places of Italian MAs, which - as in many other European countries are the result of a coalescence process rather than of a simple decentralisation of employment from a congested CBD. Density measures, indeed, are based on this latter idea. From an empirical point of view, on the other hand, the two compared procedures of identification do not show the same results. The functional approach allows the identification of the nodes that can be considered sub-centres in a more restricted sense, while with the density threshold of Giuliano and Small, many high-density municipalities surrounding the CBDs are also thought of as sub-centres.

Further developments should examine if there are different kinds of sub-centres that differ in terms of their origin - decentralisation or coalescence. Hence, it should be worth investigating if different kinds of sub-centres have different impacts on metropolitan spatial structure. This could be investigated by looking at the way in which sub-centres relate to one another and by seeing to what extent the functions they play are alternative or complementary. In order to do this, however, other connections should be explored, such as consumption and leisure activities and inter-firm exchanges.

\section{References}

Alonso, W. (1964), Location and Land Use, Cambridge: Harvard University Press.

Anas, A., Arnott, R. and Small, K.A. (1998), Urban Spatial Structure, Journal of Economic Literature XXXVI, 1426-1464.

Anderson, N.B. and Bogart, W.T. (2001), The Structure of Sprawl. Identifying and Characterizing Employment Centers in Polycentric Metropolitan Areas, American Journal of Economics and Sociology 60, 147-169.

Anselin, L. (1995), Local indicators of spatial association - LISA. Geographical Analysis 27, 93-116.

Barbonne, R., Villeneuve P., and Thériault M. (2007), The spatial dynamics of local labour markets within Quebec city metropolitan field: 1981-2001, The Canadian Geographer 51(3), 303-322.

Batten, D.F. (1995), Network cities: creative urban agglomerations for the 21st century, Urban Studies 32, 313-327.

Baumont, C. and Bourdon, F. (2002), Centres secondaires et recomposition économique des espaces urbains.Le cas de la Communauté de l'Agglomération Dijonnaise (1990; 1999). LATEC, Laboratoire d'Analyse et des Techniques EConomiques, Université de Bourgogne CNRS UMR 5118. 
Baumont, C., Ertur, C. and Le Gallo, J. (2004), Spatial Analysis of Employment and Population Density : The Case of the Agglomeration of Dijon 1999, Geographical Analysis 36, 146-176.

Bender, B. (1981), Urban Housing Density and the Price of Housing Services, Journal of Urban Economics 9, 80-84.

Bender, B. (1985), Hedonic Housing Price Indices and Secondary Employment Centers, Journal of Urban Economics 17, 90-107.

Bogart, W.T. and Ferry, W.C. (1999), Employment Centres in Greater Cleveland: Evidence of Evolution in a Formerly Monocentric City, Urban Studies 36, 20992110.

Boix, R. (2002), Instrumentos de análisis de redes en economía urbana: caracterización de redes de ciudades mediante el análisis de cuatro estructuras urbanas simuladas. In $V$ Encuentro de Economia Aplicada. Oviedo.

Boix, R. and Veneri, P. (2009), Meropolitan Areas in Spain and Italy, IERMB Working Paper in Economics 09.01.

Bourne, L.S. (1989), Are New Urban Forms Emerging? Empirical Tests for Canadian Urban Areas, The Canadian Geographer 33, 312-327.

Burns, M.C., Boix, M. and Roca, J. (2001), Contrasting Indications of Polycentrism within Spain's Metropolitan Urban Regions. In Paper for the Eight European Estate Society Conference. Alicante.

Calafati, A.G. (2002), Sistemi locali: esercizi di identificazione in L. Malfi and D. Martellato (eds.), Il ruolo del capitale nello sviluppo locale e regionale, Milan: Franco Angeli.

Calafati, A.G. (2009), Macro-regions, Local Ststems, and Cities: the Conceptualisation of Territory in Italy since 1950, Scienze Regionali / Italian Journal of Regional Science 8(3) (Special Issue), 11-34.

Calafati, A.G. and Veneri, P. (2010), Re-defining the boundaries of major Italian cities, Quaderni di Ricerca, n. 342, Dipartimento di Economia, Università Politecnica delle Marche, Ancona, IT.

Camagni, R. and Salone C. (1993), Network urban structures in northern Italy: elements for a theoretical frame work, Urban Studies 30(6), 1053-1064.

Cervero, R. and Wu, K.-l. (1998), Sub-centring and Commuting: Evidence from the San Francisco Bay Area, 1980-90, Urban Studies 35, 1059-1076.

Champion, A.G. (2001), A Changing Demographic Regime and Evolving Polycentric Urban Regions: Consequences for the Size, Composition and Distribution of City Populations, Urban Studies 38, 657-677.

Christaller, W. (1933), Die zentralen Orte in Suddeutschland, Jena: Gustav Fischer Verlag.

Clark, W.A.V. and Kuijpers-Linde, M. (1994), Commuting in Restructuring Urban Regions, Urban Studies 31, 465-483.

Coffey, W.J. and Shearmur, R.G. (2002), Agglomeration and Dispersion of High-order Service Employment in the Montreal Metropolitan Region, 1981-96, Urban Studies 39, 359-378.

Compagnucci F. (2009), Dai Sistemi Locali del Lavoro alle Città: verso un nuovo algoritmo di regionalizzazione, Quaderni di Ricerca, n. 335, Dipartimento di Economia, Università Politecnica delle Marche, Ancona, IT. 
Costembader, E. and Valente, T.W. (2003), The stability of centrality measures when networks are sampled, Social Networks 25, 283-307.

Craig, S.G. and Ng, P.T. (2001), Using Quantile Smoothing Splines to Identify Employment Subcenters in a Multicentric Urban Area, Journal of Urban Economics 49, 100-120.

Davoudi, S. (2003), Polycentricity in European spatial planning: from an analytical tool to a normative agenda, European Planning Studies 11, 979-999.

Dematteis, G. (1990), Modelli urbani a rete. Considerazioni preliminari. In Gerarchie e reti di città: tendenze e politiche(Eds, Curti, F. and Diappi, L.), Milan: Franco Angeli.

Derudder, B., Taylor, P.J., Witlox, F. and Catalano G. (2003), Hierarchical tendencies and regional patterns in the world city network: a global urban analysis of 234 cities, Regional Studies 37(9), 875-886.

Forstall, R.L. and Greene, R.P. (1997), Defining job concentrations: the Los Angeles case, Urban Geography 18, 705-739.

Freeman, L.C. (1979), Centrality in social networks: conceptual clarification. Social Networks 1, 215-239.

Gilli, F. (2002), Déplacements domicilie-travail et organisation du Bassin parisien, L'Espace Géographique 31(4), 289-306.

Giuliano, G. and Small, K.A. (1991), Subcenters in the Los Angeles Region, Regional Science and Urban Economics 21, 163-182.

Gordon, P. and Richardson, H.W. (1996), Employment decentralization in US metropolitan areas: is Los Angeles an outlier or the norm?, Environmental and Planning A 28, 1727-1743.

Gordon, P., Richardson, H.W. and Giuliano, G. (1989), Travel Trends in non-CBD Activity Centers. In Report, Ca/11/0032. Washington D.C.: Urban Mass Transit Administration, US Department of Transportation.

Gordon, P., Richardson, H.W. and Wong, H.L. (1986), The distribution of population and employment in a polycentric city: the case of Los Angeles, Environmental and Planning A 18, 161-173.

Guillain, R., Le Gallo, J. and Boiteux-Orain, C. (2004), The Evolution of the Spatial and Sectoral Patterns in Ile-De-France over 1978-1997, LEG Working Paper Economie 2004/02.

Holly, H. (1993), Metropolitan Structure and the suburban hierarchy, American Sociological Review 58(3), 417-433.

Jacobs, J. (1969), The Economy of Cities, New York: Random House.

Leslie, T.F. (2010), Identification and Differentiation of Urban Centers in Phoenix Through a Multi-Criteria Kernel-Density Approach, International Regional Science Review 33(2), 205-235.

Limtanakool, N., Dijst, M. and Schwanen, T. (2007), A theoretical framework and methodology for characterizing National urban systems on the basis of flows of people: empirical evidence for France and Germany, Urban Studies 44(11), 21232145.

Limtanakool, N., Schwanen, T. and Dijst, M. (2009), Development in the Dutch Urban System on the basis of flows, Regional Studies 43(2), 179-196.

Lukermann, F. (1966), Empirical expressions of nodality and hierarchy in a circulation manifold, East Lakes Geographer, 2, 17-44. 
Kemper, P. and Schmenner, R. (1974), The density gradient for manufacturing industry, Journal of Urban Economics 4, 410-427.

Lösch, A. (1940), Die Räumliche Ordnung der Wirstchaft, Jena: Gustav Fischer.

McDonald, J.F. (1987), The Identification of Urban Employment Subcenters, Journal of Urban Economics 21, 242-258.

McDonald, J.F. and McMillen, D.P. (1990), Employment Subcenters and Land Values in a Polycentric Urban Areas: the Case of Chicago, Environment and Planning A 22, 1561-1574.

McDonald, J.F. and Prather, P.J. (1994), Suburban Employment Centres: The Case of Chicago, Urban Studies 31, 201-218.

McMillen, D.P. (2001), Nonparametric Employment Subcenters Identification, Journal of Urban Economics 50, 448-473.

McMillen, D.P. and Lester, W.T. (2003), Evolving subcenters: employment and population densities in Chicago, 1970-2020, Journal of Housing Economics 12, 6081.

Meijers, E.J. and Burger, M.J. (2010), Spatial structure and productivity in US metropolitan areas, Environment and Planning A, Vol. 42, No. 6, pp. 1383-1402.

Mills, E.S. (1972), Studies in the Structure of the Urban Economy, Baltimore: John Hopkins Press.

Muñiz, I., Galindo, A. and García López, M.A. (2005), Decentralisation, Integration and Polycentrism in Barcelona. Document de Treball - Department d'Economia Aplicada, Universitat Autònoma de Barcelona 5.12.

Muth, R. (1969), Cities and Housing, Chicago: University of Chicago Press.

Office of Management and Budget (1990), Revised standards for defining metropolitan areas in the 1990s, Federal Register 55, 12154-12160.

Redfearn, C.L. (2007), The Topography of Metropolitan Employment: Identifying Centers of Employment in a Polycentric Urban Area, Journal of Urban Economics 61, 519-541.

Richardson, H.W. (1995), Economies and diseconomies of agglomeration, in $\mathrm{H}$. Giersch (eds.), Urban Agglomeration and Economic Growth, Berlin: Springer, 123155.

Riguelle, F., Thomas, I. and Verhetsel, A. (2007), Measuring Urban Polycentrism: a European Case Study and its Implications, Journal of Economic Geography 7, 193215.

Shearmur, R.G. and Coffey, W.J. (2002), A Tale of Four Cities: Intrametropolitan Employment Distribution in Toronto, Montreal, Vancouver and Ottawa - Hull, 1981 - 1996, Environment and Planning A 34, 575-598.

Shearmur, R.G. and Motte B. (2009), Weak Ties that Bind. Do Commutes Bind Montreal's Central and Suburban Economies?, Urban Affairs Review 44(4), 490-524.

Small, K.A. and Song, S. (1994), Population and Employment Densities: Structure and Change, Journal of Urban Economics 36, 292-313.

Song, S. (1994), Modelling Worker Residence Distribution in the Los Angeles Region, Urban Studies 31, 1533-1544.

Zemljič, B. and Hlebec, V. (2005), Reliability of measures of centrality and prominence, Social Networks 27, 73-88. 